\title{
Managing gestational diabetes: the role of patient counselling
}

\author{
Ammulu S. ${ }^{1}$, Fasalu Rahiman O. M. ${ }^{2 *}$, Muhammed Rasheeq K. P. ${ }^{3}$
}

\author{
${ }^{1}$ Department of Obstetrics and Gynecology, Amala Medical College, Thrissur, Kerala, India \\ ${ }^{2}$ Department of Pharmacology, MES Medical College, Malappuram, Kerala, India \\ ${ }^{3}$ Department of Pharmacy practice, JDT college of pharmaceutical science, Kozhikode, Kerala, India
}

Received: 31 December 2018

Accepted: 05 February 2019

\section{*Correspondence:}

Dr. Fasalu Rahiman OM,

E-mail: fasaluom@gmail.com

Copyright: (C) the author(s), publisher and licensee Medip Academy. This is an open-access article distributed under the terms of the Creative Commons Attribution Non-Commercial License, which permits unrestricted non-commercial use, distribution, and reproduction in any medium, provided the original work is properly cited.

\begin{abstract}
Background: Unmanaged gestational diabetes mellitus (GDM) increases the risk of neonatal and fetal complications and the risk of congenital malformations. Apart from the medications used, non-pharmacological agents such as diet modification, exercise, and patient education can improve the quality of life in GDM patients. The present study was aimed to evaluate the role of patient counselling in the management of GDM in patents.

Methods: Unmanaged gestational diabetes mellitus (GDM) increases the risk of neonatal and fetal complications and the risk of congenital malformations. Apart from the medications used, non-pharmacological agents such as diet modification, exercise, and patient education can improve the quality of life in GDM patients. The present study was aimed to evaluate the role of patient counseling in the management of GDM in patents.

Results: The result showed that there is a slight increase in the QOL of test population with GDM. i.e., there is no significant progression in the disease condition. The result showed that each domain, physical, psychological, social and environmental conditions were improved a lot when compared with the control group.

Conclusions: Results suggests a positive impact of patient counseling on the management of GDM in patients.
\end{abstract}

Keywords: Gestational diabetes mellitus, Patient counseling, Pregnancy

\section{INTRODUCTION}

Diabetes mellitus, a metabolic disorder characterised by chronic hyperglycemia with disturbances of carbohydrate, fat and protein metabolism resulting from defects in insulin secretion, insulin action or both. The prevalence of diabetes for all age groups worldwide was estimated to be $2.8 \%$ in 2000 and $4.8 \%$ in $2030{ }^{1}$ Gestational diabetes mellitus (GDM) is a common metabolic disorder that occurs during pregnancy. GDM can cause significant problems, including maternal complications, perinatal complications, and metabolic disorders in the offspring of mothers with GDM. The incidence of this condition is increasing reflecting the increasing prevalence of obesity and metabolic syndrome. ${ }^{2}$ The trend towards older maternal age, adoption of modern lifestyle, changing eating habits and reduced physical activity may contribute towards an increased prevalence of GDM. Pregestational and gestational diabetes pose many risks to the mother and fetus. The consequences of diabetes lead to increased maternal and fetal morbidity. One of the most severe complications of GDM is the increased risk of developing preeclampsia, which occurs in $10 \%$ of patient with GDM. ${ }^{3}$ The risk of preeclampsia is around $35-60 \%$ in women who have microalbuminuria in early pregnancy. ${ }^{4}$ Other complications of GDM include preterm labour, chorioamnionitis polyhydramnios, urinary tract infections and others. In the condition during the antepartum period like febrile illness, dehydration from hyperemesis or diarrheal disease can precipitate ketoacidoses which can be life threatening not only for mother but may also cause sudden fetal death. Increased risks of obstetric 
complications such as increased incidence of pregnancyinduced hypertension, caesarean section, bradytocia, and induction of childbirth are common during GDM. Increased risks of prenatal complications such as increased incidence of macrosomia, delayed intrauterine fetal development, neonatal complications (hypoglycemia, polycythemia, hyperbilirubinemia), etc are also common with GDM populations. In the case of GDM, there is an increased risk of the mother developing type 2 diabetes in future. The fetal risks are mainly such as Growth abnormalities: macrosomia, growth restriction and malformations, chemical imbalances after birth, fetal oxygenation problems: sudden fetal demise, chronic fetal hypoxia and respiratory distress syndrome, long-term sequelae. Hence the study was designed to find the drug utilisation pattern and to evaluate the quality of life of the patient after patient counselling by using counselling aids.

\section{METHODS}

A prospective observational study was conducted at the department of obstetrics and gynaecology, Iqra International Hospital and Research Centre, a tertiary level referral hospital having the capacity of 300 beds. The study consist of all pregnant women who are newly diagnosed with diabetes mellitus in outpatient and inpatient units of Obstetrics and Gynecology department for seven months (November 2015- May 2016).

\section{Inclusion criteria}

- All pregnant women with gestational diabetes mellitus visiting OBG department, who are willing to participate in the study were included in the present study.

\section{Exclusion criteria}

- All pregnant women without gestational diabetes, a patient with pre-existing diabetes mellitus, and patients who are not willing to participate in the study were excluded from the study.

\section{Data collection}

Data were collected by direct patient interview using questionnaire and from case records which contain patient demographics, history, laboratory reports, and prescription.

\section{Study design}

Total study population was divided into two groups; one is the intervention or test group and a control group. Patient details were collected and documented from the direct interview, lab reports, case file and prescription to collect demographic details and medication history. Patients were asked to fill WHO-Bref Questionnaire. After filling of this intervention group were received counselling about details of the disease, pharmacological treatment, diet therapy, and exercise with the help of patient counselling aid. Then follow up done after one month and distribute the same questionnaire and changes in the quality of domain score were evaluated and compared with the control population.

\section{Statistical analysis}

Data collected from the study was tabulated in Microsoft Excel 2010 and were keyed into the SPSS and analyzed by appropriate statistical methods.

\section{RESULTS}

The study was aimed to improve the quality of life of patients with GDM with an objective to access the prevalence of gestational diabetes, analyse the risk factors of GDM and role of patient counselling in the management of gestational diabetes in the study population.

Table 1: Risk factors during GDM.

\begin{tabular}{|c|c|c|c|}
\hline \multicolumn{2}{|l|}{ Risk factors } & Frequency & $\%$ \\
\hline \multirow{4}{*}{ BMI } & Underweight & 3 & 05.5 \\
\hline & Normal weight & 28 & 51.8 \\
\hline & Over weight & 20 & 33.3 \\
\hline & Obese & 3 & 09.2 \\
\hline \multirow{3}{*}{ Trimester } & First & 8 & 14.8 \\
\hline & Second & 27 & 50.0 \\
\hline & Third & 19 & 35.2 \\
\hline \multirow{2}{*}{ Residing } & Village & 23 & 42.59 \\
\hline & Town & 31 & 57.41 \\
\hline \multirow{5}{*}{$\begin{array}{l}\text { Educational } \\
\text { category }\end{array}$} & Illiterate & 3 & 05.5 \\
\hline & Literate till $10^{\text {th }}$ & 15 & 27.7 \\
\hline & HSC & 21 & 38.8 \\
\hline & Degree & 13 & 24.3 \\
\hline & P.G and Above & 2 & 03.7 \\
\hline \multirow{3}{*}{$\begin{array}{l}\text { Economic } \\
\text { category }\end{array}$} & Poor-class & 14 & 25.9 \\
\hline & Middle-class & 38 & 70.4 \\
\hline & Upper-class & 2 & 03.7 \\
\hline \multirow{2}{*}{$\begin{array}{l}\text { Occupational } \\
\text { category }\end{array}$} & Employed & 09 & 16.6 \\
\hline & Un-employed & 45 & 83.4 \\
\hline \multirow{3}{*}{ Parity } & First & 32 & 59.9 \\
\hline & Second & 16 & 29.0 \\
\hline & Third & 6 & 11.1 \\
\hline \multirow{2}{*}{$\begin{array}{l}\text { Family } \\
\text { history of } \\
\text { DM }\end{array}$} & Yes & 38 & 70.3 \\
\hline & Non & 16 & 29.7 \\
\hline \multirow{2}{*}{$\begin{array}{l}\text { History of } \\
\text { GDM }\end{array}$} & Yes & 18 & 33.3 \\
\hline & No & 36 & 66.7 \\
\hline \multirow{2}{*}{$\begin{array}{l}\text { High BP on } \\
\text { medication } \\
\text { during } \\
\text { pregnancy }\end{array}$} & Yes & 9 & 16.6 \\
\hline & No & 45 & 83.4 \\
\hline \multirow{2}{*}{$\begin{array}{l}\text { Thyroid } \\
\text { diseases }\end{array}$} & Yes & 12 & 22.2 \\
\hline & No & 42 & 77.8 \\
\hline
\end{tabular}


From the hospital record, it was found that 1980 pregnant women have visited in the OBG department during the study period, out of these 54 patients are selected to study who met inclusion criteria having a prevalence of $2.72 \%$. Certain risks factors tend to the development of gestational diabetes mellitus observed in the study population are listed in the Table 1 . The family history of diabetes mellitus was found as the major risk factors for developing GDM among the test group. Patient having body mass index of greater than 25 , were also in risk to develop GDM. History of GDM, overweight and obese, BP medication, and thyroid disease are the other risk factors. Other than this, factors such as gestational age act as a significant risk factor for the development of GDM.

The commonly used methods for the management of gestational diabetes mellitus in the study population are listed in Table 2. Both pharmacological and nonpharmacological therapy was used to manage the GDM in the study population. Insulin therapy, a combination of insulin and non-pharmacological treatment, oral hypoglycemic agent (OHA), insulin therapy and OHA were used in the management of GDM. Highest choice management of GDM was found to be a combination of insulin and diet therapy.
Table 2: Comparison of management option for GDM.

\begin{tabular}{|l|l|l|}
\hline Types & Frequency & Percentage \\
\hline Diet alone & 13 & 24.1 \\
\hline Diet + Insulin & 17 & 31.5 \\
\hline Insulin alone & 16 & 29.6 \\
\hline OHA+ Insulin & 2 & 3.7 \\
\hline OHA & 6 & 11.1 \\
\hline Total & 54 & 100 \\
\hline
\end{tabular}

The WHOQOL- BREF examines the quality of life profile among the participants. A total of 20 Patients included in the control group without giving any patient counselling. The mean score obtained for each domain in the WHOQOL-BREF are listed in the Table 3. A total of 34 Patients included in the intervention group. The result showed that there is a slight increase in the QOL of test population with GDM. i.e., there is no significant progression in the disease condition. The result showed that each domain, physical, psychological, social and environmental conditions were improved a lot when compared with the control group. That suggests that there is a positive impact on patient counseling on GDM patients.

Table 3: Overall WHOQOL-BREF mean domain Scores $(\mathbf{n}=54)$.

\begin{tabular}{|c|c|c|c|c|}
\hline Whoqol-Bref domain & Study population & Base-line & Follow-up & P-value \\
\hline \multirow{2}{*}{ Whoqol-Bref-I (physical) } & Control group & $53 \pm 2.32$ & $59.2 \pm 2.071$ & \multirow{2}{*}{$0.0432 *$} \\
\hline & Intervention group & $55.35 \pm 1.135$ & $67 \pm 0.8886$ & \\
\hline \multirow{2}{*}{ Whoqol-Bref-II (psychological) } & Control-group & $57.25 \pm 1.549$ & $59.8 \pm 1.291$ & \multirow{2}{*}{$0.0384 *$} \\
\hline & Intervention group & $59.44 \pm 1.063$ & $69.82 \pm 0.9089$ & \\
\hline \multirow{2}{*}{ Whoqol-Bref-III (social) } & Control-group & $67.8 \pm 2.353$ & $68.9 \pm 2.254$ & \multirow{2}{*}{$0.0473 *$} \\
\hline & Intervention group & $63.29 \pm 1.53$ & $72.26 \pm 1.206$ & \\
\hline \multirow{2}{*}{ Whoqol-Bref-IV (environmental) } & Control-group & $59.5 \pm 1.754$ & $61.8 \pm 1.733$ & \multirow{2}{*}{$0.0434 *$} \\
\hline & Intervention group & $58.62 \pm 0.8338$ & $67.56 \pm 0.6392$ & \\
\hline
\end{tabular}

\section{DISCUSSION}

Gestational diabetes mellitus (GDM) is one of the common disorders in pregnancy related to inappropriate glucose tolerance. The management of GDM required proper medical therapy by a physician and need implement of education and adequate counseling to patients. The complications of GDM are known to affect the quality of life of patients.

Various factors like understanding of patient about the disease, dietary regulation, self-monitoring of blood glucose level, self-administration of insulin are known to play a vital role in the management and increasing quality of life. ${ }^{5}$ The prevalence of study population based on age range in the current study has found to be among the patients who were in the age range of 28-35 years and less common in patient with age below 20 years respectively. Due to this fact women with weight gain and hormonal changes are seen during the 18-34 age period. This was a similar finding of a study conducted by Naila Tabassam et al. ${ }^{6}$ The women with overweight and obese are increased the risk of gestational diabetes mellitus, in this current study showing 20 patients are overweight and three patients are obese there understood overweight and obese is a risk factor of developing of GDM. These result similar to the finding of a study by Rajput $\mathrm{R}$ et al. $^{7}$ The present study shows a high prevalence of gestational diabetes mellitus during the second trimester, which is identical to the finding of Naila Tabassam et al. ${ }^{6}$ It is due to the fact of screening done by glucose challenging test, glucose tolerance test, random and fasting blood sugar level were found in the second trimester of pregnancy. Patients residing in town area more tend to develop GDM because of inappropriate 
lifestyle and busy life schedules. Patient with low education was found to be more prevalent to develop gestational diabetes mellitus.

Interaction of patient with low education was a complicated procedure because of inadequate knowledge about the disease, future complication, lack of awareness about diagnosis and proper management of the disease lead to increase in prevalence. GDM have a high prevalence in women with first parity or successive parity. These facts the no of parity increases associated with risk factors like increasing age, body weight, and fat deposition also increases. These results are similar to a study conducted by Junhongleng et al. ${ }^{8}$ There are several risk factors which tend to develop GDM.

The family history of diabetes mellitus in the first degree of relatives has a strong correlation with the occurrence of GDM. In the present study, 38 patients (70.3\%) having a family history of diabetes mellitus, it is to be higher due to genetic reasons. History of GDM, family history of DM, high BP medication during pregnancy, were found $18(33.3 \%), 38(70.3 \%)$, and $9(16.6 \%)$ are respectively. Twenty-three patients $(42.6 \%)$ with BMI $>25 \mathrm{~kg} / \mathrm{m}^{2}$ were at risk of development of GDM. All these increases the occurrence of gestational diabetes mellitus, these results are correlated with the finding of the study conducted by Sediggheh Sohilykhan et al. ${ }^{9}$

The management of gestational diabetes by insulin therapy, diet therapy and oral hypoglycaemic agent are commonly used. In the present study insulin therapy along with diet modification appears to be more effective in the management of GDM, there 17 patients were advised to follow a regular meal plan along with insulin therapy for the control of the current situation.

There were similar findings of the study conducted by Akhila Sivadas et al. ${ }^{10}$ The insulin therapy is commonly used for the management of GDM due to the lack of safety of hypoglycaemic agent during pregnancy. ${ }^{11}$ The use a WHO-Bref questionnaire could be helpful for accessing the quality of life of the GDM patients.

The WHO-Bref questionnaire consists of 26 questions, in 4 domains: it consists of physical, physiological, social and environmental as well as an assessment of the quality of life.

A relatively higher score was obtained for social functioning and physical health. As a result of patient counseling, physical health was improved. The increased physical health increases the social functioning of the patients. A worse score was obtained for psychological and environmental factors. Mental function of the GDM patients impaired due to negative feelings about the disease and decreased the degree of sleep. This decreased mental health may affect the ecological functioning of the patients.

\section{CONCLUSION}

The risk factors to the development of GDM was found to be a family history of GDM, history of GDM, BMI $>25 \mathrm{~kg} / \mathrm{m}^{2}$, and increased age. Study reports the need of better life modifications such as appropriate meal plan with medical therapy for the management of gestational diabetes mellitus. The WHOQOL-BREF from the GDM shows an effect in physiological and environmental aspect of health in the patients. Study report that the physiological and environmental aspect of health seems to be the most affected GDM. Proper counselling and awareness regarding the disease and disease management can improve the quality of the life of the patients thereby reducing the risk factors of gestational diabetes mellitus.

\section{ACKNOWLEDGMENTS}

Authors would like to thank Iqra International Hospital and Research Centre and Medi research direct for their support during the entire project.

\section{Funding: No funding sources}

Conflict of interest: None declared

Ethical approval: The study was approved by the Institutional Ethics Committee

\section{REFERENCES}

1. Whiting DR, Guariguata L, Weil C, Shaw J. IDF diabetes atlas: global estimates of the prevalence of diabetes for 2011 and 2030. Diab Res Clinic Practice. 2011;94(3):311-21.

2. Boney CM, Verma A, Tucker R, Vohr BR. Metabolic syndrome in childhood: association with birth weight, maternal obesity, and gestational diabetes mellitus. Pediat. 2005;115(3):e290-6.

3. McDonald SD, Malinowski A, Zhou Q, Yusuf S, Devereaux PJ. Cardiovascular sequelae of preeclampsia/eclampsia: a systematic review and meta-analyses. Am Heart J. 2008;156(5):918-30.

4. Chirayath HH. Diabetes management in pregnancy. Reviews in Gynaecol Perinat Prac 2006;6(1-2):10614.

5. Redmon B, Caccamo D, Flavin P, Michels R, O'Connor P, Roberts J, Smith S, Sperl-Hillen J. Diagnosis and management of type 2 diabetes mellitus in adults. Institute Clinic Syst Improve 2014;16(7):1-83.

6. Tabassam N, Sadaqat F, Mahmood KT, Zaka M. Prevention and Management of Gestational Diabetes Mellitus. J Pharmaceut Sci Technol. 2010;2(12):404410.

7. Rajput R, Yadav Y, Nanda S, Rajput M. Prevalence of gestational diabetes mellitus and associated risk factors at a tertiary care hospital in Haryana. The Indian J Medical Res. 2013;137(4):728.

8. Magon N, Seshiah V. Gestational diabetes mellitus: Non-insulin management. Indian $\mathrm{J}$ Endocrinol Metabol. 2011;15(4):284-293. 
9. Soheilykhah S, Mogibian M, Rahimi-Saghand S, Rashidi M, Soheilykhah S, Piroz M. Incidence of gestational diabetes mellitus in pregnant women. Int J Reproduct BioMed. 2010;8(2):24-0.

10. Calou CG, Pinheiro AK, Castro RC, de Oliveira MF, de Souza Aquino P, Antezana FJ. Health related quality of life of pregnant women and associated factors: An integrative review. Health. 2014;6(18):2375.

11. American Diabetes Association. Standards of medical care in diabetes-2015 abridged for primary care providers. Clinic Diab: Am Diab Ass. 2015;33(2):97.

Cite this article as: Ammulu S, Rahiman FOM, Rasheeq MKP. Managing gestational diabetes: the role of patient counselling. Int $\mathrm{J}$ Reprod Contracept Obstet Gynecol 2019;8:1011-5. 